\title{
Seasonal fluctuation in diurnal rhythms of luteinizing hormone secretion in ewes during the mid-luteal phase of the oestrous cycle
}

\author{
W. D. Currie*, R. J. Medhamurthy†, S. J. Cook and N. C. Rawlings \\ Veterinary Physiological Sciences, University of Saskatchewan, Saskatoon, Saskatchewan, \\ Canada, S7N oWo
}

\begin{abstract}
Diurnal and seasonal fluctuations were detected in luteinizing hormone (LH) interpulse interval, but not amplitude, in ewes examined during the mid-luteal phase of an oestrous cycle at five stages of the breeding season. Daytime and night-time LH interpulse intervals were greater in the early and late than in the mid-breeding season $(P<0.05)$. During the early and late breeding season, $\mathrm{LH}$ interpulse interval was less during daylight than during darkness $(P<0.05)$. Toward the mid-breeding season, interpulse interval decreased during daytime earlier in the season than the night-time decrease. It was concluded that the diurnal fluctuations observed are a component of a circannual rhythm in LH secretion resulting from gradual seasonal transitions in photoperiodic drive to, or an endogenous rhythm in, the hypothalamic-pituitary axis in ewes.
\end{abstract}

\section{Introduction}

Diurnal profiles of gonadotrophin secretion in ewes do not appear to have been extensively examined. There is evidence for diurnal rhythms in luteinizing hormone (LH) secretion in ewes (Walton et al., 1980; Rhind et al., 1990) and rams (Lincoln and Peet, 1977; Lincoln et al., 1977; Ortavant et al., 1982). However, no evidence of diurnal fluctuations in episodic LH or folliclestimulating hormone (FSH) secretion was observed using a 12 min sampling interval in ewes in the mid-luteal phase of an oestrous cycle or ovariectomized ewes during mid-breeding season (Currie and Rawlings, 1989). In addition, there was no evidence of diurnal fluctuations in $\mathrm{LH}$ or FSH secretion using an hourly sampling interval in ewes during the follicular phase of an oestrous cycle (Currie et al., 1991). There is stronger evidence of diurnal rhythms in gonadotrophin secretion for primates (Soules et al., 1985; Filicori et al., 1986; Ji et al., 1989). In contrast to the lack of clarity on the existence of diurnal rhythms in LH secretion in ewes, clear circannual rhythms exist (Karsch et al., 1984). Marked changes in LH secretion occur at the onset and cessation of the breeding season in ewes (Karsch et al., 1984) and a more subtle circannual rhythm may occur (Joseph et al., 1992). The purpose of this study was to examine $24 \mathrm{~h}$ circulating LH profiles in ewes during the mid-luteal phase of oestrous cycles at five stages of the breeding season for diurnal and seasonal fluctuations.

\section{Materials and Methods}

\section{Animals}

Six Columbia ewes were kept in a paddock and fed pelleted lucerne ( $1.2 \mathrm{~kg}$ per ewe per day; fed between 09:00 and 10:00 h), *Present address: Obstetrics and Gynaecology, University of British Columbia, Vancouver, British Columbia V6H 3 V 5.

†Present address: Department of Physiology, University of Pittsburgh, School of Medicine, Pittsburgh, PA 15261, USA.

Received 30 December 1991. with hay, mineralized salt and water freely available. Oestrus was synchronized at the approximate onset of the breeding season for this breed by a 12-day treatment with medroxyprogesteroneacetate-releasing intravaginal sponges (Veramix, Tuco, Orangeville, ON). In a previous study, $80 \%$ of a flock of Columbia ewes were cycling by early September and $80 \%$ were anoestrous by mid-February (Jeffcoate et al., 1984). A markerharnessed, vasectomized ram was housed with the ewes for oestrus detection. Day 0 of the oestrous cycle was considered the day by which at least four of six ewes displayed oestrus. Onset of oestrus remained synchronized in these ewes to within 2 days all season, over eight oestrous cycles.

\section{Experiment}

On day 8 of the synchronized oestrous cycle, the ewes and ram were confined to a $3 \mathrm{~m} \times 3 \mathrm{~m}$ roofed, but open-fronted, wooden shelter within the paddock the ewes were kept in; the animals normally had free access to this shelter. The ewes were provided with food and water as in the larger paddock. In addition, on day 8 of the synchronized cycle, the ewes were catheterized in both jugular veins with vinyl tube (i.d. $1.00 \mathrm{~mm}$, o.d. $1.50 \mathrm{~mm}, \mathrm{SV}-70$, Dural Plastics and Engineering, Dural, $\mathrm{NSW})$. Beginning at $12: 00 \mathrm{~h}$ on day 9 , blood samples $(3 \mathrm{ml})$ were collected via catheters at intervals of $10 \mathrm{~min}$ for $24 \mathrm{~h}$. Blood samples were collected, as above, beginning at 12:00 h on day 9 of every second subsequent oestrous cycle. At night, moonlight was sufficient to sample blood of ewes, but a red light was used for sample handling. Blood was allowed to clot for $\mathrm{I} \mathrm{h}$ at $21^{\circ} \mathrm{C}$ and for a further $4 \mathrm{~h}$ at $4^{\circ} \mathrm{C}$. Clots were removed and serum was centrifuged at $1570 \mathrm{~g}$ for $15 \mathrm{~min}$, harvested and stored at $-20^{\circ} \mathrm{C}$ until analysed. Catheters were removed at the conclusion of each observation period and replaced 1 day prior to each subsequent observation period. Ewes were allowed access to the larger paddock area after the $24 \mathrm{~h}$ of blood sampling. 
Luteinizing hormone assay

Serum LH concentrations were determined by radioimmunoassay (Currie and Rawlings, 1989) and expressed in terms of NIDDK-oLH. Assay sensitivity was $0.1 \mathrm{ng} \mathrm{LH} \mathrm{ml}{ }^{-1}$ serum (lowest standard different from zero by unpaired $t$ test, $P<0.05$ ). Intra- and interassay coefficients of variation were 4.6 and $6.9 \%$, respectively (mean $=2.4 \mathrm{ng} \mathrm{ml}^{-1}$ serum), 6.0 and $8.9 \%$ (mean $=$ $1.6 \mathrm{ng} \mathrm{ml}^{-1}$ serum) and 6.6 and $11 \%$ (mean $=0.5 \mathrm{ng} \mathrm{ml}^{-1}$ serum).

\section{Data analysis}

Circulating LH profiles were analysed for mean and basal LH concentration and $\mathrm{LH}$ interpulse interval and pulse amplitude (Currie and Rawlings, 1989) with Pulsar (Merriam and Wachter, 1982) modified for interactive use with IBM-compatible microcomputers (J. F. Gitzen and V. D. Ramirez, University of Illinois). Standard deviation criteria and the interpolating function for the assay standard curve were taken from large blocks of LH data and ovine LH assays, respectively, from our previous work. Comparison of LH parameters between observation periods and daylight versus darkness was by two-way analysis of variance for repeated measures and Newman-Keuls multiple comparisons (True Epistat, 3rd edn, Epistat Services, Richardson, TX).

\section{Results}

During the observation periods used across the breeding season, $45 \%$ of $\mathrm{LH}$ pulses occurred during daylight. When weighted for proportionate daily differences between hours of daylight and darkness, $59 \%$ of LH pulses occurred during daylight. Analysis of variance revealed a significant effect of observation period and daylight versus darkness on $\mathrm{LH}$ interpulse interval $(P<0.05)$, but not on LH pulse amplitude $(P>0.05)$. The interaction of main effects was also significant for $\mathrm{LH}$ interpulse interval. Basal and mean serum LH concentrations consistently approximated to the sensitivity of the LH assay. Daytime and night-time $\mathrm{LH}$ interpulse intervals were greater in the early and late than in the mid-breeding season ( $P<0.05$, Fig. 1). $\mathrm{LH}$ interpulse interval was less during daylight than during darkness during the second (31 October) and final (13 February) observation periods (Fig. $1, P<0.05$ ), but did not differ during the first observation period (26 September) or during observation periods in the mid-breeding season $(6$ December, 10 January; $P>0.05$ ). LH interpulse interval decreased earlier in the breeding season during daylight than during darkness (6 December versus 31 October). There was an apparent period of reduced episodic $\mathrm{LH}$ secretion at about sunrise in three ewes during the last observation period (13 February, Fig. 2). Otherwise, LH pulses were fairly regularly distributed during daylight and during darkness. The mean oestrous cycle length for the period from the first oestrus following synchronization until the oestrus just prior to the last period tested was $17.5 \pm 0.4$ days.

\section{Discussion}

The results of the present work suggested that, on day 9/10 of the oestrous cycle, during the early and late breeding season in
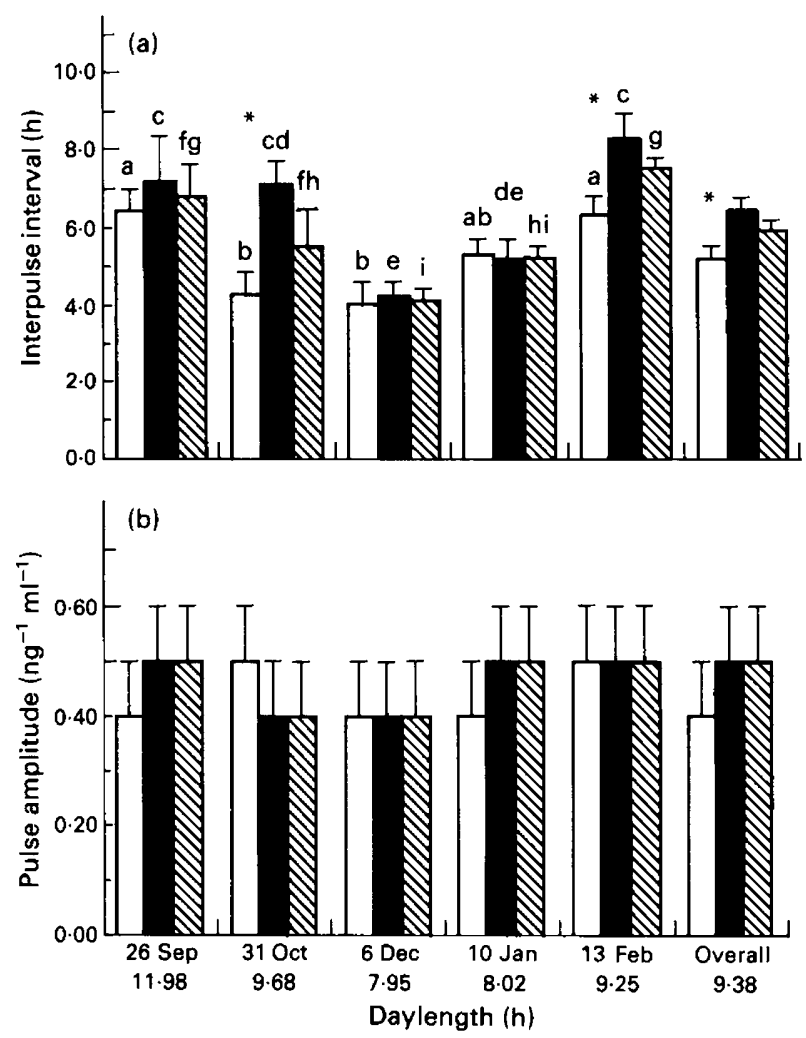

Fig. 1. Serum luteinizing hormone (a) interpulse interval and (b) pulse

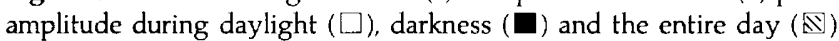
for ewes blood sampled for $24 \mathrm{~h}$ between days 9 and 10 of the oestrous cycle at five times during the breeding season. Values are means \pm SEM. Times beneath dates are daylengths (sunrise to sunset). The letter superscripts show significant differences $(P<0.05)$ between dates but

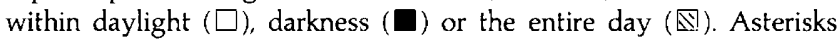
show differences between darkness and daylight $(P<0.05)$.

ewes, LH interpulse interval was less during daylight than in darkness. This seasonal pattern in diurnal variation of $\mathrm{LH}$ interpulse interval may explain why in previous studies we failed to see a diurnal rhythm in $\mathrm{LH}$ secretion in ovariectomized or intact ewes in the luteal phase of an oestrous cycle (Currie and Rawlings, 1989; Currie et al., 1991). The latter studies were done close to the mid-breeding season. In anoestrous ewes, $\mathrm{LH}$ interpulse interval appeared to be reduced shortly after dawn (Walton et al., 1980), and, in intact cyclic ewes on day 10 of an oestrous cycle, mean circulating concentrations of LH were higher during the day than at night (Rhind et al., 1990). In the study of Rhind et al. (1990), the increased LH concentrations during daytime were probably due to a reduced LH interpulse interval.

Similar studies in rams have produced more equivocal results. Some studies suggested that LH concentrations were low during daylight, particularly early in the day and highest during darkness (Lincoln and Peet, 1977; Lincoln et al., 1977), whereas the results of other work showed the reverse: increased LH secretion 3-9 h after dawn (Ortavant et al., 1982).

Evidence exists for diurnal rhythms in gonadotrophin secretion in primates. Diurnal rhythms in LH secretion have been detected in women, with increased night-time LH interpulse 

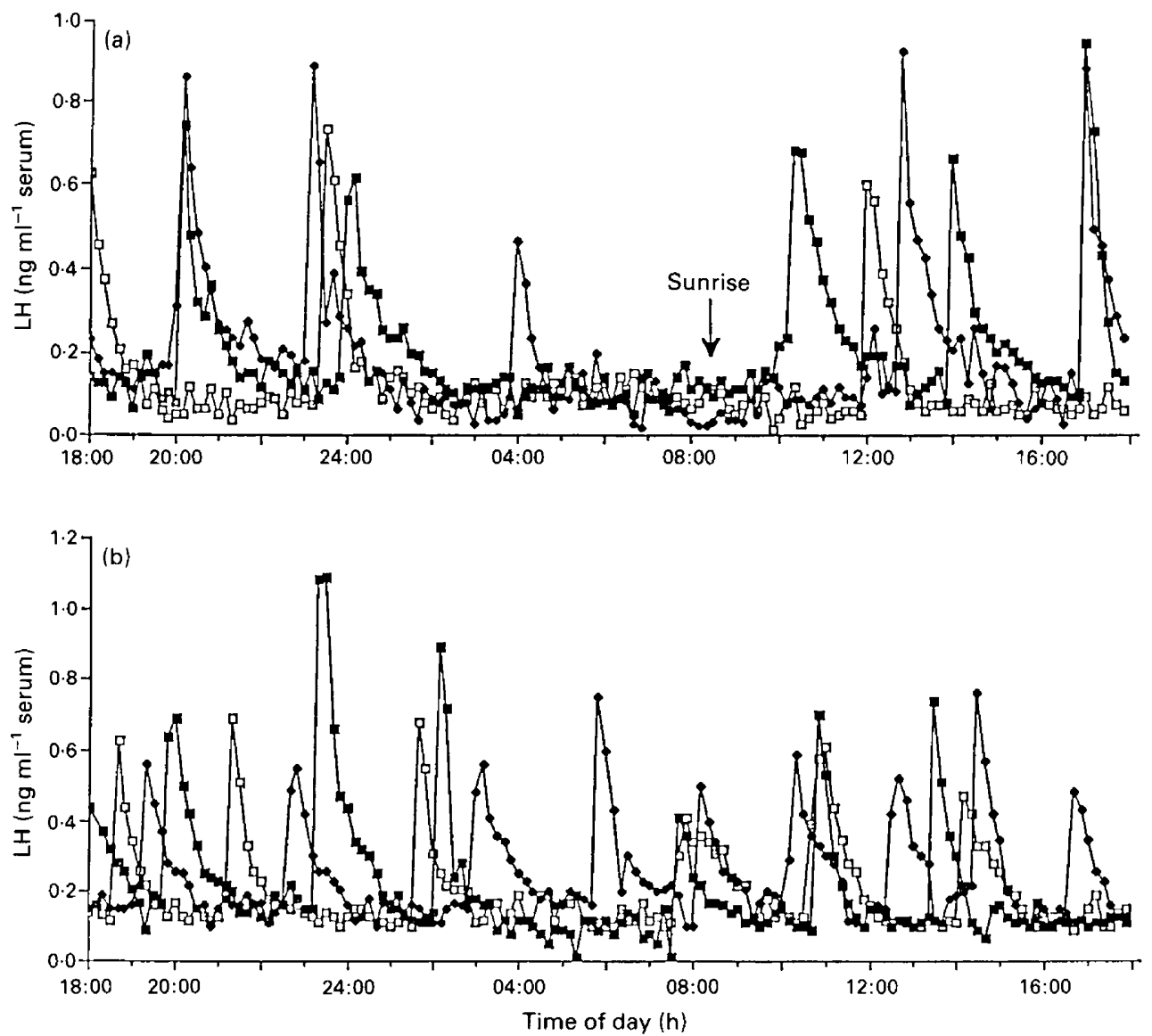

Fig. 2. Circulating concentrations of luteinizing hormone (LH) over $24 \mathrm{~h}$ in ewes at the mid-luteal phase of an oestrous cycle close to the end of the breeding season (13 February). Sunrise was at 08:30 h and sunset at 18:12 h. At this period of observation, episodic LH secretion was reduced at about sunrise in three ewes (a: $\square \square$ ), but not in the other three ewes studies (b: $\square \square$ ).

interval in the early to mid-follicular phase of the menstrual cycle (Soules et al., 1985; Filicori et al., 1986). In contrast, nighttime LH interpulse interval may be reduced during the luteal, but not the follicular, phase of the menstrual cycle in macaque monkeys (Ji et al., 1989).

Diurnal rhythms in LH secretion have been related to activity cycles in rams (Lincoln and Peet, 1977), with suppression of LH secretion during daytime activity. The converse in our ewes, greater $\mathrm{LH}$ secretion in daytime, would suggest that increased central nervous system activity during waking hours and times of increased central nervous system activity associated with feeding and other activity resulted in reduced LH interpulse intervals. We do not think the diurnal rhythms observed were artificial, as we maintained daily husbandry patterns, merely confining the ewes to a smaller area of their paddock for the purpose of blood collection. The differences in LH secretion observed between night and day could reflect a true diurnal rhythm, as a result of changes in other hormonal or neurotransmitter systems. For example, increased night-time LH interpulse interval in women in the early to mid-follicular phase of the menstrual cycle (Soules et al., 1985; Filicori et al., 1986) and in macaque monkeys during the follicular phase of the menstrual cycle may result from heightened opioid activity (Ji et al., 1989).

If the diurnal patterns in LH secretion seen in our work were cued by photoperiod, the mechanism is unclear. Photoperiod is the primary cue regulating seasonal fluctuation in tonic secretion of the hypothalamic-pituitary-ovarian axis (Karsch, 1987) and nightly melatonin secretion is the primary transduction mechanism for photoperiodic influences on this axis (Karsch et al., 1984). Long nights of melatonin exposure enhance LH secretion over periods of weeks (Karsch, 1987). Melatonin, therefore, is unlikely to be a cause of the longer $\mathrm{LH}$ pulse intervals seen at night in our present study.

In this study, LH interpulse interval during the mid-luteal phase of the oestrous cycle was greatest near the beginning and end of the breeding season. Toward the mid-breeding season, LH interpulse interval decreased during daytime earlier in the season than the night-time decrease. Thus, the diurnal trends appeared to be a component of a larger seasonal trend in LH secretion. A subtle change in LH secretion during the breeding season has been seen in some (Joseph et al., 1992), but not all, studies (Robinson et al., 1985). The lack of synchrony of changes in LH interpulse interval between day and night over the breeding season in our work could reflect diurnal patterns in neurotransmitter influences on $\mathrm{LH}$ secretion as discussed for primates earlier (Soules et al., 1985; Filicori et al., 1986; Ji et al., 1989).

Optimum fertility in ewes is achieved at mid-breeding season (Ortavant $e$ t al., 1988). This fits the shifts in LH interpulse interval seen in our study, where interpulse interval was not only 
shortest at mid-breeding season, but similar for night and day. The subtle change in $\mathrm{LH}$ secretion during the breeding season may reflect a steroid independent or dependent regulatory mechanism (Joseph et al., 1992). The changes in LH interpulse interval seen over the breeding season in our work appeared to mirror changes in daily photoperiod. However, this has to be tempered by the knowledge that photoperiod changes influence reproductive events with a lag phase of many weeks (Rawlings, 1987). Perhaps the seasonal and diurnal patterns we observed in LH interpulse interval reflect endogenous rhythms in ewes (Karsch, 1987; Joseph et al., 1992).

Diurnal trends in $\mathrm{LH}$ secretion in ewes in the mid-luteal phase of the oestrous cycle show subtle shifts across the breeding season. Circannual transitions in $\mathrm{LH}$ secretion in sheep would appear to include these shifts across the breeding season as well as more abrupt changes in and out of anoestrus (Joseph et al., 1992). Gradual seasonal transitions in gonadotrophin secretion have been observed in Père David's deer hind (Curlewis et al., 1991). Evidence obtained here suggested that the diurnal trends in LH secretion are a subtle component of a larger circannual trend in LH secretion and the seasonality of reproduction or, more specifically, of fertility within the breeding season.

This work was supported by the Canadian National Sciences and Engineering Research Council. We thank M. Buckley and staff for animal care and NIDDK for LH standards.

\section{References}

Curlewis JD, McLeod BJ and Loudon AS (1991) LH secretion and response to $\mathrm{GnRH}$ during seasonal anoestrus of the Père David's deer hind (Elaphurus davidianus) Journal of Reproduction and Fertility 91 131-138

Currie WD and Rawlings NC (1989) Prolonged infusion of morphine and naloxone in the ewe: fluctuation in responsiveness of $\mathrm{LH}$ and lack of responsiveness of FSH Journal of Reproduction and Fertility 86 359-366

Currie WD, Joseph IBJK and Rawlings NC (1991) Morphine, naloxone and the gonadotrophin surge in ewes Journal of Reproduction and Fertility 92 $407-414$

Filicori M, Santoro N, Merriam GR and Crowley WF (1986) Characterization of the physiological pattern of episodic gonadotropin secretion throughout the human menstrual cycle Journal of Clinical Endocrinology and Metabolism 62 $1136-1144$
Jeffcoate IA, Rawlings NC and Howell WE (1984) Duration of the breeding season and response to reproductive manipulation in five breeds of sheep under northem prairie conditions Theriogenology 22 279-290

Ji WZ, Kaynard AH, Pau KY, Hess DL, Baughman WL and Spies HG (1989) Endogenous opiates regulate the nocturnal reduction in luteinizing hormone pulse frequency during the luteal phase of the macaque menstrual cycle Biology of Reproduction 41 1024-1033

Joseph IBJK, Currie WD and Rawlings NC (1992) Effects of time after ovariectomy, season and oestradiol on luteinizing hormone and folliclestimulating hormone secretion in ovariectomized ewes journal of Reproduction and Fertility 94 511-523

Karsch FJ (1987) Central actions of ovarian steroids in the feedback regulation of pulsatile secretion of luteinizing hormone Annual Reviews of Physiology 49 365-382

Karsch FJ, Bittman EL, Foster DL, Goodman RL, Legan SJ and Robinson JE (1984) Neuroendocrine basis of seasonal reproduction Recent Progress in Hormone Research 40 184-232

Lincoln GA and Peet MJ (1977) Photoperiodic control of gonadotrophin secretion in the ram: a detailed study of the temporal changes in plasma levels of follicle stimulating hormone, luteinizing hormone and testosterone following an abrupt switch from long to short days Journal of Endocrinology 74 355-367

Lincoln GA, Peet MJ and Cunningham RA (1977) Seasonal and circadian changes in the episodic release of follicle stimulating hormone, luteinizing hormone and testosterone in rams exposed to artificial photoperiods Journal of Endocrinology $72337-349$

Merriam GR and Wachter KW (1982) Algorithms for the study of episodic hormone secretion American Joumal of Physiology 243 E310-318

Ortavant R, Daveau A, Garnier DH, Pelletier J, De Reviers MM and Terqui M (1982) Diurnal variation in release of LH and testosterone in the ram Journal of Reproduction and Fertility 64 347-353

Ortavant R, Bocquier F, Pelletier J, Ravault JP, Thimonier J and Volland-Nail P (1988) Seasonality of reproduction in sheep and its control by photoperiod Australian Journal of Biological Sciences $\mathbf{4 1}$ 69-85

Rawlings NC (1987) Reproductive activity in Finnish Landrace $\times$ Rambouillet ewes exposed to various daylength cycles applied over periods of six months Theriogenology 28 33-42.

Rhind SM Wetherill GZ and Gunn RG (1990) Diurnal profiles of LH prolactin and progesterone and their relationships in ewes in high or moderate levels of body condition Animal Reproduction Sciences 4 119-126

Robinson JE, Radford HM and Karsch FJ (1985) Seasonal changes in pulsatile luteinizing hormone (LH) secretion in the ewe: relationship of frequency of $\mathrm{LH}$ pulses to daylength and the response to oestradiol negative feedback Biology of Reproduction 33 324-334

Soules MR, Steiner RA, Cohen NL, Bremner WJ and Clifton DK (1985) Nocturnal slowing of pulsatile luteinizing hormone secretion in women during the follicular phase of the menstrual cycle Joumal of Clinical Endocrinology and Metabolism $6143-49$

Walton JS, Evins JD, Fitzgerald BP and Cunningham FJ (1980) Abrupt decrease in daylength and short term concentrations of FSH, LH and prolactin in anoestrous ewes Journal of Reproduction and Fertility 59 163-171 